\title{
Comparative analysis of a monoclonal- antibody-based immunofluorescence test for plasmacytoid leukemia in chinook salmon Oncorhynchus tshawytscha
}

\author{
G. C. Newbound ${ }^{1, *}$, R. J. F. Markham ${ }^{1}$, M. L. Kent ${ }^{2}$, D. J. Speare ${ }^{1}$, M. A. Thorburn ${ }^{3}$ \\ ${ }^{1}$ Department of Pathology and Microbiology, Atlantic Veterinary College, University of Prince Edward Island, \\ 550 University Ave., Charlottetown, Prince Edward Island, Canada C1A 4P3 \\ ${ }^{2}$ Biological Sciences Branch, Department of Fisheries and Oceans, Pacific Biological Station, Nanaimo, British Columbia, \\ Canada V9R 5K6 \\ ${ }^{3}$ Department of Population Medicine, Ontario Veterinary College, University of Guelph, Guelph, Ontario, Canada N1G 2 W1
}

\begin{abstract}
Plasmacytoid leukemia (PL) is a lymphoproliferative disorder that affects netpen-reared chinook salmon Oncorhynchus tshawytscha in British Columbia, Canada. The only diagnostic test for $\mathrm{PL}$ is histologic evaluation of suspect fish. Monoclonal antibodies (MAbs) previously reported to react with tissues of PL-affected fish were used in a quantitative indirect fluorescence antibody (IFA) test. These MAbs reacted with a $75 \mathrm{kDa}$ antigen that is highly expressed in tissues of fish with PL. Using experimentally infected fish, the sensitivity, specificity, and predictive values of the IFA test were compared to those of the standard histologic test. The IFA test was determined to have a sensitivity of $72 \%$, which was significantly higher than that of histologic examination, and could detect experimental infection at 3 wk post-injection, earlier than histologic examination. The sensitivity and practicality of the IFA test will enable it to be a useful screening test for the detection of PL.
\end{abstract}

KEY WORDS: Plasmacytoid leukemia - Chinook salmon Oncorhynchus tshawytscha Indirect fluorescence antibody test

\section{INTRODUCTION}

Plasmacytoid leukemia (PL) has been diagnosed in netpen-reared chinook salmon Oncorhynchus tshawytscha in British Columbia, Canada, since 1988 (Kent et al. 1990). The disease is characterized by proliferation and infiltration of cells described as plasmablasts within hemopoietic tissues, particularly kidney and spleen, and non-hemopoietic tissues, especially liver, lamina propria of posterior intestine, and retrobulbar tissue (Kent et al. 1990). PL can be experimentally transmitted to chinook salmon (Kent \& Dawe 1990) as well as other species of salmonids (Newbound \& Kent 1991) by a single intraperitoneal injection of tissue

- Present address: Department of Veterinary Biosciences, 1925 Coffey Road, The Ohio State University, Columbus, Ohio 43210-1092, USA homogenates prepared from infected fish. Experimentally infected fish typically show clinical signs of PL (Kent et al. 1990) and die within $16 \mathrm{wk}$ post-injection.

Although the etiology has yet to be proven, recent work supports the hypothesis of Kent et al. (1990) that $\mathrm{PL}$ is caused by an oncogenic retrovirus. Kent \& Dawe (1993) demonstrated transmission of PL by injecting cell-free filtrates, and Eaton \& Kent (1992) showed significant levels of reverse transcriptase activity associated with virus particles having a morphology and buoyant density consistent with known retroviruses. Eaton \& Kent (1992) named the retrovirus associated with PL as salmon leukemia virus (SLV).

The test currently available to diagnose PL is histologic evaluation of affected fish (Kent et al. 1990, Newbound \& Kent 1991) but it has 3 important limitations. First, many naturally and experimentally infected fish are concurrently infected with Renibacterium salmoni- 
narum, the etiologic agent of bacterial kidney disease (BKD). BKD is characterized by diffuse, multi-organ, granulomatous inflammation (Bruno 1986) making the histologic diagnosis of PL challenging. Second, experimentally infected fish sampled at less than 4 wh postinjection rarely exhibit the full set of criteria (Kent \& Dawe 1993) necessary to make a histologic diagnosis of PL. These 2 limitations cause the present diagnostic procedures for PL to be relatively insensitive. The third limitation is that histologic examination of tissue sections is a relatively slow and expensive method of diagnosing fish diseases, which is one reason it has not been possible to determine the prevalence and economic impact of PL.

We have previously produced 2 monoclonal antibodies (MAbs) which reacted, by immunofluorescence, with an antigen present in the cytoplasm and plasma membrane of plasmablasts, monocytes, granulocytes, and platelets of infected fish (Newbound et al. 1993). The reactive cells were demonstrated within tumour tissue imprints from kidney, spleen, and retrobulbar tissues made from fish naturally and experimentally infected with PL. The 2 objectives of the present study were to identify and initially characterize the antigen that is recognized by the PL-reactive MAbs, and to compare a quantitative MAb-based indirect fluorescence antibody (IFA) test with histologic methods for PL detection.

\section{MATERIALS AND METHODS}

Establishment of infection and sampling of fish. Approximately 300 chinook salmon $(70 \mathrm{~g})$ were injected intraperitoneally with $0.5 \mathrm{ml}$ of pooled tissue homogenate made from kidneys and spleens of PLpositive fish as previously described (Kent \& Dawe 1990, Newbound \& Kent 1991). The donor fish were naturally infected, with full clinical and histopathological expression of PL. Three donor fish were used and their kidneys and spleens were removed, frozen for brief storage, and then homogenized in saline 11 part tissue : 5 parts saline). Approximately 200 fish were not injected and used as controls. The fish were obtained from a PL-free freshwater hatchery (Rosewall Creek Hatchery, Department of Fisheries and Oceans) located on Vancouver Island, British Columbia, Canada. The injected fish were housed in six $650 \mathrm{I}$ tanks with approximately 55 fish per tank. Control fish were kept in two $1500 \mathrm{l}$ tanks at a density of approximately 250 fish per tank. All fish were supplied with filtered seawater at ambient temperature. The fish were arbitrarily dipnet-sampled by the schedule shown in Table 1 The sampling intervals of major interest were Weeks 1,4 and 7. In excess of 30 fish
Table 1. Numbers of injected and non-injected Oncorhynchus tshawytscha sampled by week post-injection

\begin{tabular}{ccc|}
\hline Week & Non-injected & Injected \\
\hline 1 & 45 & 45 \\
2 & 10 & 10 \\
3 & 10 & 10 \\
4 & 34 & 36 \\
5 & 10 & 20 \\
6 & 10 & 19 \\
7 & 44 & 45 \\
8 & 4 & 4 \\
\hline
\end{tabular}

were collected for each of those weeks. Smaller samples were taken at Weeks 2, 3, 5, 6 and 8 only to determine if some brief temporal events in antigen expression were occurring which might later become covert. The study was terminated at $8 \mathrm{wk}$ postinjection due to an epizootic of BKD. This epizootic resulted in fewer fish being sampled during the latter period of the experiment

Purification of antigen. Murine $\operatorname{IgG}_{1} \mathrm{MAb}$ was produced in vitro as previously described (Newbound et al. 1993). Immunoglobulin was purified from tissue culture fluids using an affinity column containing Protein $G$ Sepharose 4 Fast Flow beads (Pharmacia, Baie d'Urfe, Quebec, Canada). Purified antibodies were used to prepare an immunoaffinity column according to the manufacturer's instructions (ImmunoPure Ag/Ab Immobilization Kit \#3, Pierce, Rockford, IL, USA). Ten milligrams of purified MAbs in $1.0 \mathrm{ml}$ of sodium phosphate buffer (20 mM), pH 7.0, were used according to the protocol.

Total cellular proteins were prepared from pooled kidney and spleen tissues (2.94 g) from an experimentally infected chinook salmon following methods of Harlow \& Lane (1988). Detergent lysis of monolayer cultures was accomplished using octylphenol-ethylene oxide (NP-40, Sigma, St. Louis, MO, USA) lysis buffer (150 mM NaCl, $1 \%$ NP- $40,50 \mathrm{mM}$ Tris buffer), pH 8.0 , with $100 \mu \mathrm{g} \mathrm{ml^{-1 }}$ phenylmethylsufonyl fluoride (Sigma).

Protein extracts were centrifuged at $10000 \times g$ for $10 \mathrm{~min}$ at $4^{\circ} \mathrm{C}$. Supernatant was removed and dialysed overnight at $4^{\circ} \mathrm{C}$, with 2 changes of Tris buffer $(50 \mathrm{mM})$ containing the detergent sodium deoxycholate $(0.5 \%)$. The proteins were then dialysed for $24 \mathrm{~h}$ at $4^{\circ} \mathrm{C}$ against sodium phosphate buffer $(20 \mathrm{mM}), \mathrm{pH} 7.0$, with 4 changes of buffer. The detergent-purified proteins were stored at $4^{\circ} \mathrm{C}$ for $1 \mathrm{~h}$ before immunoaffinity purification.

Immunoblotting (Western blotting) was used to determine reactivity of the PL-reactive MAbs with the following protein preparations: detergent-purified proteins before the immunoaffinity column; detergent- 
purified proteins eluted from the immunoaffinity column; SLV proteins purified by continuous sucrosegradient density centrifugation and sodium dodecylsulfate polyacrylamide gel elecrophoresis (SDS-PAGE) (Eaton \& Kent 1992); proteins from infected tissue purified by discontinuous sucrose-gradient density centrifugation (Eaton \& Kent 1992); and a whole-cell preparation of Renibacterium salmoninarum. Controls included PL-reactive MAbs against an irrelevant bacterial protein (Flexibacter sp.), and irrelevant murine IgG, MAbs with the above protein preparations. SDSPAGE was performed on a Mini-Protean II slab cell electrophoresis unit (Bio-Rad, Richmond, CA, USA) according to the manufacturer's protocol. After SDSPAGE, proteins were electrophoretically transferred to a $0.45 \mu \mathrm{m}$ nitrocellulose membrane according to manufacturer's instructions (Bio-Rad Mini-protean II device).

Immunoblots were performed following the procedure of Harlow \& Lane (1988). The nitrocellulose membrane was blocked overnight at $4^{\circ} \mathrm{C}$ with $2 \%$ bovine serum albumin in Tris-buffered saline (TBS) $(20 \mathrm{mM}$ Tris and $500 \mathrm{mM} \mathrm{NaCl}$, pH 7.5. The membrane was incubated with $20 \mu \mathrm{g} \mathrm{ml}^{-1}$ of the purified antibody in TBS for 30 min, and then washed with $0.05 \%$ Tween 20 (J.T. Baker Chemical Co., Phillipsburg, NJ, USA) in TBS for 15 min. Secondary antibody was rabbit antimouse IgG (FC specific) conjugated with alkaline phosphatase (Jackson ImmunoResearch Laboratories, West Grove, PA, USA) diluted 1:1000 in 2\% bovine serum albumin in TBS and incubated for $30 \mathrm{~min}$. The membrane was washed as before. The substrate ( $p$-nitroblue tetrazolium chloride, and 5-bromo-4-chloro-3indolyl phosphate in $70 \%$ dimethylformamide) was prepared according to manufacturer's specifications (Bio-Rad) and was incubated with the membrane until lines were visible in approximately 15 min

Protein samples were run on duplicate gels. One gel was used for immunoblotting, while the second was silver-stained for total protein detection (Silver Stain Kit for Polyacrylamide Gels \#AG-25 and AG-5, Sigma).

Carbohydrate detection of the protein eluted from the immunoaffinity column was performed using the GlycoTrack Carbohydrate Detection Kit (K-050, Oxford Glycosystems, Rosedale, NY, USA) using the protocol for proteins transferred to a nitrocellulose membrane.

Indirect fluorescence antibody test. Fish were killed by spinal severance and $1 \mathrm{~cm}^{3}$ sections of posterior kidney and spleen were dissected. These sections were used to make 6 imprints from each organ on Shandon 12-well multispot microscope slides (John's Scientific, Dartmouth, N.S., Canada). One slide was used per fish and 6 kidney imprints were placed in the top row of wells while the 6 spleen imprints were placed in the lower 6 wells. The imprints were air dried and immediately fixed with a 60:40 acetone: $100 \%$ ethanol solution at $-20^{\circ} \mathrm{C}$ for $10 \mathrm{~min}$, and were stored at $-70^{\circ} \mathrm{C}$ with a desiccant.

The IFA test was performed as previously described (Newbound et al. 1993). The primary and secondary antibodies were incubated for 30 min each and washes were for 10 min each. Primary antibody consisted of hybridoma tissue culture supernatant as previously described (Newbound et al. 1993). The secondary antibody was rabbit anti-mouse $\operatorname{IgG}+\mathrm{A}+\mathrm{M}(\mathrm{H}+\mathrm{L})$ conjugated with fluorescein isothiocyanate (Zymed Laboratories, San Francisco, CA, USA). The primary MAbs were incubated on 4 of the 6 imprints of each organ as follows. The first imprint ( 1 of 6 ) was incubated with positive polyclonal sera from immunized mice ( $\mathrm{New}$ bound et al. 1993) as a positive control. The second imprint ( 2 of 6 ) was incubated with culture fluids from the myeloma cell line used for the original fusion and was the negative control. The next 2 imprints ( 3 and 4 of 6) were incubated with the first MAb and the last 2 imprints ( 5 and 6 of 6 ) with the second MAb.

The slides were blindly read (G.C.N.) in the following manner. After confirmation of the positive and negative controls on each slide, 10 randomly chosen fields at $400 \times$ magnification were selected from each of the 8 tissue imprints incubated with the MAbs. All fluorescing cells in the chosen fields were subjectively given a numerical score of 1,2 or 3 corresponding to the level of fluorescence exhibited by each cell, and the scores for each imprint were totalled. The fluorescence scores from each of the 8 imprints were then totalled ( 80 fields per slide) to give a total fluorescent score per slide.

Histopathology. Sections of posterior kidney, spleen, liver, pyloric cecae, and posterior intestine were dissected from each fish during the time that the tissue imprints were being made. These tissues were fixed in Davidson's solution (Humason 1979). The samples were prepared for routine histologic examination and stained with hematoxylin and eosin using standard procedures. The stained sections were blindly read (G.C.N.). A fish was considered histologically positive if characteristic plasmablasts (Kent et al. 1990) were observed in large numbers in the renal interstitium and in any non-hemopoietic organ. The histologic definition of PL used in this study is the same one used for diagnostic and research purposes (Kent \& Dawe 1993).

Histologic detection of BKD was based on the description by Bruno (1986). Briefly, BKD was diagnosed by the observation of random, multifocal to coalescing granulomas within 1 or more of the sampled tissues

Statistical analysis. We used injection status of an individual fish as the indicator of the true infective state of that fish. This decision was based on previous 
work on experimentally transmitted PL (Kent \& Dawe 1990, Newbound \& Kent 1991) which indicates that the majority of injected fish become infected with PL. We believe that experimental infection best establishes known populations of positive fish.

Continuous data obtained using the IFA test were transformed to dichotomous (i.e. positive and negative) data allowing comparison with the dichotomous histologic results. A receiver-operator characteristic (ROC) curve (Sackett et al. 1985, Spangler et al. 1992) was constructed to determine the total fluorescence score that optimized sensitivity and specificity of the IFA test.

Using dichotomous data for the 2 tests, sensitivity and specificity were calculated as described by Sackett et al. (1985). The estimated sensitivities were used to calculate fish-level and farm-level predictive values at different prevalence levels (Martin et al. 1992). The fish-and farm-level positive predictive values denote the probability that an individual fish or farm truly is affected by PL given that the individual fish, or at least 1 fish in the sample from the farm, tests positive. The fish-and farm-level negative predictive values denote the probability that an individual fish or farm truly is free from PL given that the individual fish, or no fish in the sample from the farm, tests negative.

Disagreement between the IFA test and histologic testing was evaluated by performing a MCNemar's chisquared analysis (Glantz 1987) using the BMDP statistical software program (Dixon et al. 1988). Fish from which both IFA and histologic results were not available were not included in these comparisons.

Because the MAbs used in the IFA test were raised by injecting Balb/c mice with lysed tumour tissue (Newbound et al. 1993) and not the purified etiologic agent of PL, it was possible that we also inoculated the mice with contaminating Renibacterium salmoninarum. To determine if the IFA results were related to $R$. salmoninarum, or to inflammation associated with the bacterium, a log-linear analysis of IFA outcome, histological outcome, and BKD diagnosis was performed (Thorburn et al. 1982/1983, Norman \& Streiner 1986) using the BMDP statistical software package (Dixon et al. 1988).

\section{RESULTS}

\section{Antigen determination and characterization}

To identify the antigen recognized by the PL-reactive MAbs, we performed immunoblots on proteins extracted from tumour tissue of infected fish. Immunoblots indicated that the MAbs reacted with a $75 \mathrm{kDa}$ band in the detergent-purified and in the dis-

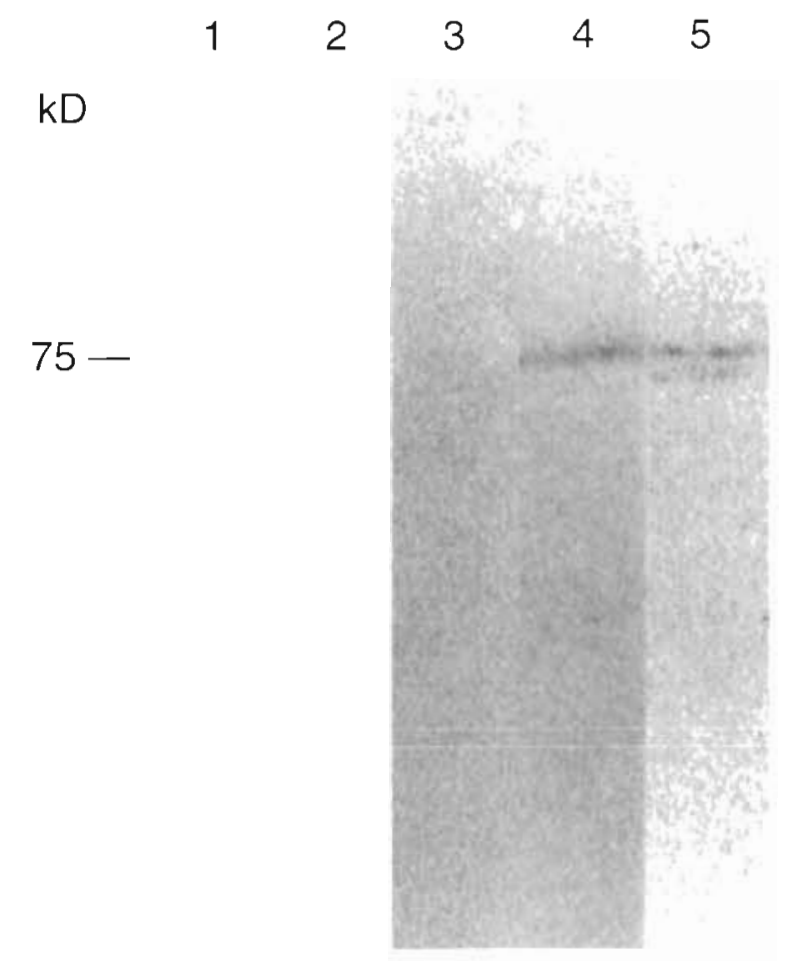

Fig. 1 Representative immunoblot utilizing PL-reactive monoclonal antibodies (Lanes 2 to 5 ) and an isotype control (Lane 1). Lanes 1 and 4 contain detergent-purified Oncorhynchus tshawytscha tumour tissue, Lane 2 contains a total protein preparation of Renibacterium salmoninarum, Lane 3 contains salmon leukemia virus proteins, and Lane 5 contains discontinuous sucrose-gradient purified tumour tissue. The $75 \mathrm{kDa}$ protein band is present in Lanes 4 and 5 , whereas no reactive proteins are evident in Lanes 1 through 3

continuous sucrose-gradient purified protein lanes, but did not react with protein preparations of Renibacterium salmoninarum nor with SLV proteins purified by continuous sucrose-gradient density centrifugation and SDS-PAGE (Fig. 1). In addition to the $75 \mathrm{kDa}$ protein band, a slightly smaller band. was variably visualized in the discontinuous sucrose-gradient purified lanes. We assumed that this smaller molecular weight band was due to protease degradation of the $75 \mathrm{kDa}$ band because a protease inhibitor was not included during this preparation, whereas one was included in the detergent-purified samples. Controls included an irrelevant murine $\operatorname{IgG}_{1} \mathrm{MAb}_{\mathrm{b}}$ that recognizes Flexibacter $\mathrm{sp}$. This irrelevant MAb did not react with any of the protein preparations tested (Fig. 1, Lane 1).

A. $75 \mathrm{kDa}$ protein was eluted from the immunoaffinity column which was detected by the PL-specfic MAbs, Staining of the protein eluted from the immunoaffinity column with the carbohydrate stain did not reveal any bands. This suggests that the protein was non-glycosylated. 


\section{Indirect fluorescence antibody test}

After determining the antigen to which the PL-reactive MAbs react, we utilized the MAbs in an IFA test and blindly compared IFA test results to histologic diagnoses of injected and non-injected fish. We found that the IFA test was more sensitive than histologic methods, whereas histologic testing was more specific (Table 2). Additionally, the IFA test was also able to detect at least $50 \%$ of the injected fish starting at 3 wk post-injection, whereas histologic testing first detected positive fish at $4 \mathrm{wk}$ post-injection (Fig. 2) and in only $11 \%(4$ of 36 ) of the fish.

The ROC curve indicated that the total fluorescence score of 21 optimized both sensitivity and specificity for the IFA test. Overall, the IFA results yielded a sensitivity of $72 \%$ and a specificity of $76 \%$ (Table 2). Conversely, histologic analysis yielded a sensitivity of $32 \%$ and a specificity of $100 \%$ (Table 2). Comparison of the IFA test results to histologic diagnoses of both the

Table 2. Oncorhynchus tshawytscha. Comparison of positive $(+)$ and negative (-) indirect fluorescence antibody (IFA) and histologic (HIST) results for PL in injected and non-injected tish

\begin{tabular}{lccc|}
\hline & Injected & Non-injected & Total \\
\hline IFA+ & 93 & 25 & 118 \\
IFA- & $\frac{37}{130}$ & $\overline{81}$ & $\frac{118}{236}$ \\
Total & & & \\
HIST + & 40 & 103 & 189 \\
HIST - & $\frac{86}{126}$ & $\overline{103}$ & 229 \\
Total & & & \\
IFA sensituvity: & $93 / 130=72 \%$ & \\
IFA sensitivity: $81 / 106=76 \%$ & \\
HIST sensitivity: & $40 / 126=36 \%$ & \\
HIST sensitivity: & $103 / 103=100 \%$ & \\
\hline
\end{tabular}

Table 3. Oncorhynchus tshawytscha. Comparison of positive $(+)$ and negative $(-)$ histologic results (HIST) with indirect fluorescence antibody test (IFA) results for PL, in all fish (top part of table) and in injected-only fish (bottom part)

\begin{tabular}{|lccc|}
\hline & HIST + & HIST - & Total \\
\hline IFA+ & 32 & 81 & 113 \\
IFA- & 8 & $\overline{108}$ & $\frac{116}{229}$ \\
Total & $\overline{40}$ & $\overline{189}$ & \\
IFA + & 32 & 57 & $\frac{37}{126}$ \\
IFA - & $\overline{40}$ & $\overline{29}$ & \\
Total & $\overline{86}$ & & \\
\hline
\end{tabular}

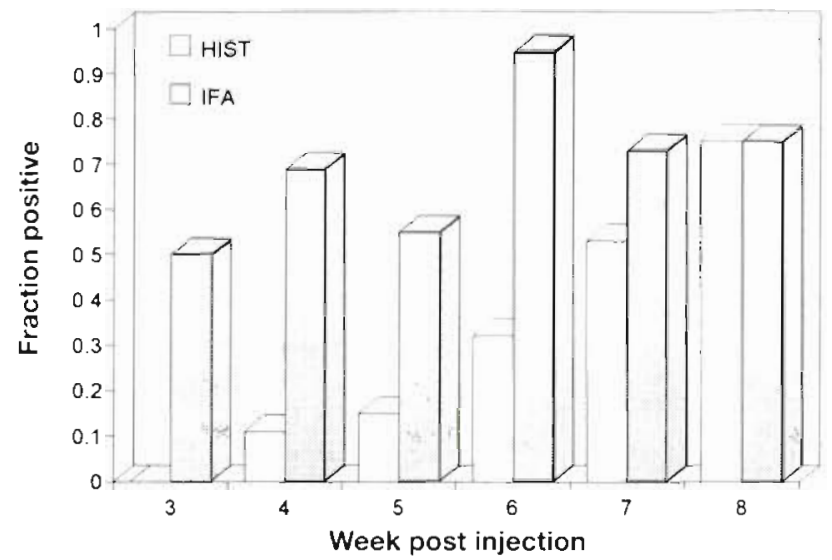

Fig. 2. Comparison of histologic diagnoses (HIST) and indirect fluorescence antibody (IFA) test results for PL by week postinjection

injected and control fish revealed a McNemar's chisquared statistic of $59.88(\mathrm{p}<0.001)$ (Table 3$)$. Therefore the 2 tests were significantly different at predicting injection status of the fish. McNemar's chi-squared analysis was also performed on the histologic and IFA results of only the injected fish (Table 3 ). This analysis yielded a statistic of $36.94(p<0.001)$ which indicated that, again, the tests performed significantly differently at predicting injection status of the injected fish, and hence had significantly different sensitivities. A similar statistical comparison of the histologic and the IFA results of the non-injected fish was not performed since the specificity of the histologic analysis was $100 \%$, and thus one of the cells in the $2 \times 2$ table would have had a value of zero (Glantz 1987).

The positive and negative predictive values at various prevalence levels for the 2 tests are listed in Table 4. Histologic testing yielded positive predictive values of $100 \%$, given that the specificity is $100 \%$. The fish-level and farm-level positive predictive values for IFA were substantially lower than those for histologic testing, particularly when the fish- and farm-level prevalences were low. However, IFA testing produced higher negative predictive values than did histologic testing, particularly when the prevalence of affected fish or farms was high (Table 4).

The contingency table for the 3 factors, injection status, IFA result and BKD diagnosis, is presented in Table 5. Initial screening of the data by chi-squared analysis indicated that: (1) injection and IFA, and (2) injection and BKD were associated ( $p<0.001$ ), whereas (3) IFA and BKD were not associated $(p=0.69)$. A log-linear model including the association between injection and IFA and the association between injection and $\mathrm{BKD}$ provided a good fit to the data (using the likelihood ratio chi-squared, $p=0.92$ ) 
Table 4 Oncorhynchus tshawytscha. Positive (PPV) and negative (NPV) predictive values of the indirect fluorescence antibody (IFA) test and histologic diagnoses (HIST) of PL at differing intra- and inter-farm level prevalences. Predictive values for histologic testing are based on specificity $=0.999$. Farm-level predictive vales are based on calling the farm positive if 1 or more fish test positive

\begin{tabular}{|c|c|c|c|c|c|c|c|}
\hline $\begin{array}{l}\text { Diagnosis } \\
\text { level }\end{array}$ & $\begin{array}{c}\text { Proportion of } \\
\text { PL-positive farms }\end{array}$ & $\begin{array}{l}\text { Prevalence within } \\
\text { PL-posituve farms }\end{array}$ & $\begin{array}{l}\text { Number of } \\
\text { fish tested }\end{array}$ & $\begin{array}{l}\text { IFA } \\
\text { PPV }\end{array}$ & $\begin{array}{l}\text { IFA } \\
\text { NPV }\end{array}$ & $\begin{array}{l}\text { HIST } \\
\text { PPV }\end{array}$ & $\begin{array}{l}\text { HIST } \\
\text { NPV }\end{array}$ \\
\hline Fish & Not applicable & $\begin{array}{l}0.05 \\
0.50\end{array}$ & $\begin{array}{l}1 \\
1\end{array}$ & $\begin{array}{l}0.14 \\
0.75\end{array}$ & $\begin{array}{l}0.98 \\
0.73\end{array}$ & $\begin{array}{l}1.00 \\
1.00\end{array}$ & $\begin{array}{l}0.97 \\
0.60\end{array}$ \\
\hline Farm & 0.05 & $\begin{array}{l}0.05 \\
0.05 \\
0.55 \\
0.50\end{array}$ & $\begin{array}{l}1.0 \\
60 \\
10 \\
60\end{array}$ & $\begin{array}{l}0.05 \\
0.05 \\
0.05 \\
0.05\end{array}$ & $\begin{array}{l}0.96 \\
0.99 \\
1.00 \\
1.00\end{array}$ & $\begin{array}{l}0.45 \\
0.37 \\
0.81 \\
0.48\end{array}$ & $\begin{array}{l}0.96 \\
0.98 \\
0.99 \\
1.00\end{array}$ \\
\hline & 0.50 & $\begin{array}{l}0.05 \\
0.05 \\
0.50 \\
0.50\end{array}$ & $\begin{array}{l}10 \\
60 \\
10 \\
60\end{array}$ & $\begin{array}{l}0.51 \\
0.50 \\
0.52 \\
0.50\end{array}$ & $\begin{array}{l}0.58 \\
1.00 \\
0.98 \\
1.00\end{array}$ & $\begin{array}{l}0.94 \\
0.92 \\
0.99 \\
0.95\end{array}$ & $\begin{array}{l}0.54 \\
0.72 \\
0.85 \\
1.00\end{array}$ \\
\hline
\end{tabular}

Adding the association between IFA and BKD to the model did not significantly improve the fit of the model $(p>0.6)$. These results indicate that within each of the 2 groups of fish (injected and non-injected), IFA result and presence of BKD were independent of one another. Hence, fish with BKD were neither more nor

Table 5. Oncorhynchus tshawytscha. Comparison of positive $(+)$ and negative $(-)$ histologic detection of $\mathrm{BKD}$, indirect fluorescent antibody (IFA) test results, and injection status of fish

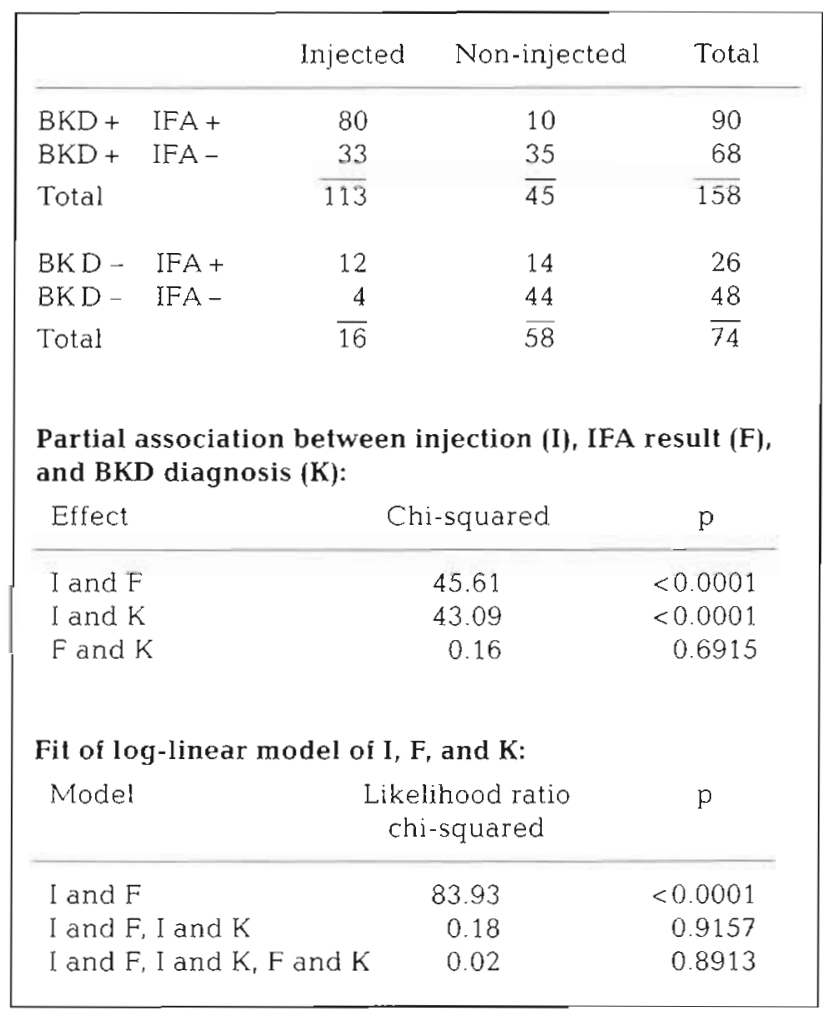

less likely to yield a positive IFA result than were fish without BKD. Also, the absence of a 3-way interaction between injection status, IFA, and $B K D$ indicates that the association between injection status and IFA result was not influenced by BKD status.

\section{DISCUSSION}

The murine $\operatorname{IgG}_{1}$ MAbs used in the IFA test reacted with a non-glycosylated $75 \mathrm{kDa}$ protein. The pattern of fluorescence indicated that this protein was expressed at high levels in the kidneys and spleens of the majority of fish experimentally infected with PL. The origin of this antigen was not determined. Possibilities include that the MAbs are reacting against viral proteins, or proteins associated with proliferation or differentiation such as gene products of cellular oncogenes.

Although the MAbs did not react with highly purified protein preparations of SLV in the instance of the continuous sucrose-gradient density centrifugation and SDS-PAGE purification, the lack of reaction does not rule out the possibility that the $75 \mathrm{kDa}$ antigen may be a viral protein, in particular an envelope protein. In other retroviral systems, for example Human T-cell Lymphotropic Virus Type-I (HTLV-I), polyclonal antibodies recognizing retroviral envelope proteins in situ have been shown not to react with purified protein (Anderson et al. 1989). It may be that the envelope protein of HTLV-I needs to be presented in association with soluble cellular lysate in order to be recognized by the antibodies. Such may be the case for the $75 \mathrm{kDa}$ antigen reactive with our MAbs because cellular proteins would be associated with the detergent-purified proteins and the proteins purified by discontinuous sucrose-gradient centrifugation, but not with viral pro- 
teins purified by continuous sucrose-gradient centrifugation. Additionally, this phenomenon is more likely to occur using MAbs as opposed to polyclonal antibodies.

The observation that the MAbs react against several morphologically distinct cells (Newbound et al. 1993) is consistent with the MAbs having specificity for viral proteins, since other retroviruses, for example Feline Leukemia Virus, Human Immunodeficiency Virus Type-I and HTLV-I, infect more than 1 cell type. Additionally, the observation that the PL-reactive MAbs did not react with proteins isolated from Renibacterium salmoninarum, and log-linear analysis demonstrating that the expression of the antigen is not associated with the inflammatory reaction evident with $\mathrm{BKD}$, are further evidence that the $75 \mathrm{kDa}$ antigen is specific for PL. Further work is necessary to test the hypothesis that the $75 \mathrm{kDa}$ antigen is viral envelope protein; however, this hypothesis does explain the previous data.

Comparison of the IFA test with the histologic results indicated that the IFA test was significantly more sensitive than histologic detection, and could detect PL earlier in the course of experimental infection. There are 3 reasons for the observed greater sensitivity of the IFA test compared with histologic diagnosis. First, results indicated that the reactive antigen was expressed earlier during experimental transmission of PL than were morphologic changes that fulfilled established diagnostic criteria for the disease. Much of the increased sensitivity of the IFA test, then, is due to its ability in predicting infection prior to morphologic changes. Second, the IFA test was not affected by concurrent BKD, whereas in this study and a previous study (Newbound \& Kent 1991), the presence of BKD diminished the ability to diagnose PL using histopathologic methods. Lastly, because PL is a newly described disease, the various histologic patterns of PL have not been fully determined. Thus a histologic diagnosis of PL must at present be based on the standard morphologic definition of the disease currently in the literature (Kent \& Dawe 1993). Adhering to this strict definition of disease causes the histologic method to be a less sensitive but conversely a more specific test.

We have estimated the sensitivity and specificity of the IFA test and histologic testing in experimentally infected fish and have based our discussion on these estimates. It is premature to assume that these estimates may be extrapolated to the general population of chinook salmon. Sensitivity values may prove to be quite different in naturally infected fish. To obtain a precise estimate of specificity will probably require testing several thousand fish (Martin 1984). Indeed, in an earlier study, we obtained a specificity estimate of $100 \%$ in a population of chinook salmon from Ontario, Canada (Newbound et al. 1993), whereas in this study our estimate was much lower.
The reason for the lower specificity in this study is unclear Our approach to estimating the specificity of the IFA test was to use a population of chinook salmon that had no history of PL. Because there is no way at present to determine the true PL status of any population, we used injection status as our definition of disease. Therefore non-injected fish that tested positive were statistically treated as false positives, resulting in a fairly low estimate of specificity. Clearly we need to determine the true PL status of various populations of fish before we can determine the accuracy of our specificity estimates for the IFA test. Also, in quantitative tests such as our IFA test, there will often be an overlap in the distribution of test values between negative and positive populations. Hence, it is not unexpected to have a small population of animals testing falsely negative as well as falsely positive (Martin 1984).

In considering the usefulness of diagnostic tests, it is important to examine predictive values. Generally, one finds that tests with high sensitivities are more useful when prevalence is high and tests with high specificities are more useful when prevalence is low. For instance, a farmer who wished to screen broodfish for PL would want to cull all the fish that test positive. If the farmer has an excess of broodfish, culling an occasional non-infected fish (false positive) is not a particularly important error. It is more important that a fish that tests negative is truly free of PL. Hence the IFA test would be the appropriate test particularly if a large proportion of the broodfish were PL-positive. The superior farm-level negative predictive value of the IFA test would also make this the appropriate test if samples of fish were being tested for PL status prior to transfer to other facilities, particularly if the prevalence of PL at the farm level was high. However, as the use of the IFA test alone would lead to approximately half of the negative lots being falsely identified as positive (given a farm-level prevalence of $50 \%$ ), it would be important to use histologic diagnostic methods as a confirmatory test in samples that tested positive. At present, IFA testing would be quite limited as a fishlevel screening test in populations with low PL prevalence, or as a farm-level screening test in areas in which only a small proportion of farms are affected with PL.

An IFA test was developed to diagnose PL due to the practicality of this technology for the aquaculture industry. The IFA procedure is one that is extensively used by fish health workers for detection of Renibacterium salmoninarum (Evelyn et al. 1981). Thus, fish health professionals are familiar with the technical aspects of an IFA test, and most well-equipped laboratories, farm sites, and hatcheries have the equipment and personnel to perform such a test. An IFA test for PL would be more rapid to perform and interpret, and be 
less expensive than histopathologic diagnostic methods. We recognize that histopathologic methods can be quantified much in the same way as the IFA test. However, morphometric analysis is even more time consuming and costly than normal histologic interpretation and tnus would be extremely impractical as a diagnostic tool. Therefore, we compared a method for interpreting IFA results that could be adapted for routine screening in conjunction with the histopathologic diagnostic methods currently used to diagnose PL. Further work must be completed, however, to standardize the IFA test between diagnostic laboratories before this test can be used on a large scale in the aquaculture industry.

Acknowledgements. This research was funded through a Department of Fisheries and Oceans/Natural Sciences and Engineering Research Council of Canddd (NSERC) Subvention Grant (Speare), an NSERC Strategic Grant, the British Columbia Ministry of Agriculture and Fisheries, and an Agriculture Canada Graduate Student Stipend to G.C.N. We thank S. Dawe and K. Whitman for technical assistance.

\section{LITERATURE CITED}

Anderson DW, Epstein JS, Lee T, et al (1989) Serologic confirmation of Human T-lymphotropic Virus Type I infection in healthy blood and plasma donors. Blood 74(7):2585-2591

Bruno, DW (1986) Histopathology of bacterial kidney disease in laboratory infected rainbow trout, Salmo gairdneri Richardson, and Atlantic salmon, Salmo salar L., with reference to naturally infected fish. J Fish Dis 9:523-527

Dixon WJ, Brown MB, Engelman L, Hill MA, Jennrich RI (1988) BMDP Statistical Software Program. University of California Press, Los Angeles

Eaton WD, Kent ML (1992) A retrovirus in chinook salmon (Oncorhynchus tshawytscha) with plasmacytoid leukemia and evidence for the etiology of the disease. Cancer Res $52: 6496-6500$

Evelyn TP, Ketcheson JE, Prosperi-Porta L (1981) The clinical significance of immunofluorescence-based diagnoses of

Responsible Subject Editor: F. M. Hetrick, College Park, Maryland, USA the bacterial kıdney disease carner Fish Pathol 15(3/4) 293-300

Glantz SA (1987) Prumer of biostatıstics. McGraw Hill Information Services Company Health Professions Division, New York

Harlow E, Lane D (1988) Antibodies: a laboratory manual. Cold Spring Harbor Laboratory, Cold Spring Harbor, NY

Humason GL (1979) Animal tissue techniques. WH Freeman Co, San Francisco

Kent ML, Dawe SC (1993) Further evidence for a viral etiology in plasmacytoid leukemia of chinook salmon Oncorhynchus tshawytscha. Dis aquat Org 15:115-121

Kent ML, Dawe SC (1990) Experimental transmission of a plasmacytoid leukemia of chinook salmon, Oncorhynchus tshawytscha. Cancer Res (Suppl) 50:5679s-5681s

Kent ML, Groff JM, Traxler GS, Zinkl JG, Bagshaw JW (1.990) Plasmacytoid leukemia in seawater reared chinook salmon Oncorhynchus tshawytscha. Dis aquat Org 8 199-209

Martin SW (1984) Estimating disease prevalence and the interpretation of test results. Prev vet Med 2:463-472

Martin SW, Shoukri M. Thorburn MA (1992) Evaluating the health status of herds based on tests applied to individuals. Prev vet Med 14:33-43

Newbound GC, Kent ML (1991) Experimental interspecies transmission of plasmacytoid leukemia in salmonid fishes. Dis aquat Org 10:159-166

Newbound GC, Markham RJ, Speare DJ, Saksida SM, Després B, Horney BS, Kibenge FS, Sheppard JA, Wright GM, Kent ML (1993) Production of monoclonal antibodies specific for antigens derived from tissue of chinook salmon, Oncorhynchus tshawytscha, affected with plasmacytoid leukemia. Am J vet Res 54(9): 1426-1431

Norman GR, Streiner DL (1986) PDQ Statistics. BC Decker Inc, Toronto

Sackett DL, Haynes RB, Tugwell P (1985) Clinical epidemiology. Little, Brown and Co, Toronto

Spangler E, Bech-Nielsen S. Heider LE, Dorn CR (1992) Interpretation of an enzyme-linked immunosorbent test using different cut-offs between positive and negative samples for diagnosis of paratuberculosis. Prev vet Med 13 . $197-204$

Thorburn MA, Carpenter TE, Jasper E, Thomas CB (1982/ 1983) The use of the log-linear model to evaluate the effects of three herd factors on Streptococcus agalactiae mastitis occurrence in California, 1977 Prev vel Med 1 $243-256$

Manuscript first received: January 25, 1994

Revised version accepted: August 9, 1994 